\title{
Corrigendum to "Serum Sclerostin Levels in Patients with Ankylosing Spondylitis and Rheumatoid Arthritis: A Systematic Review and Meta-Analysis"
}

\author{
Jianfeng Shi, ${ }^{1}$ Haijian Ying, ${ }^{2}$ Juping Du, ${ }^{1}$ and Bo Shen ${ }^{1}$ \\ ${ }^{1}$ Department of Clinical Laboratory, Taizhou Hospital of Zhejiang Province, Affiliated Hospital of Wenzhou Medical University, \\ Taizhou, Zhejiang Province, China \\ ${ }^{2}$ Wenzhou Medical University, Wenzhou, Zhejiang Province, China \\ Correspondence should be addressed to Bo Shen; shenb@enzemed.com \\ Received 7 August 2017; Accepted 12 September 2017; Published 17 October 2017 \\ Copyright (C) 2017 Jianfeng Shi et al. This is an open access article distributed under the Creative Commons Attribution License, \\ which permits unrestricted use, distribution, and reproduction in any medium, provided the original work is properly cited.
}

In the article titled "Serum Sclerostin Levels in Patients with Ankylosing Spondylitis and Rheumatoid Arthritis: A Systematic Review and Meta-Analysis" [1], the affiliation listed for the first author was incorrect. The corrected authors' list and affiliations are shown above.

\section{References}

[1] J. Shi, H. Ying, J. Du, and B. Shen, "Serum sclerostin levels in patients with ankylosing spondylitis and rheumatoid arthritis: a systematic review and meta-analysis," BioMed Research International, vol. 2017, Article ID 9295313, 7 pages, 2017. 


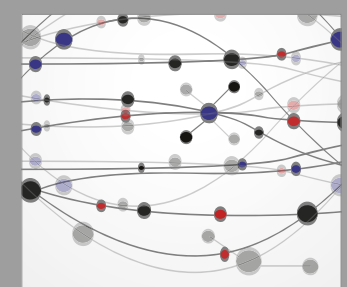

The Scientific World Journal
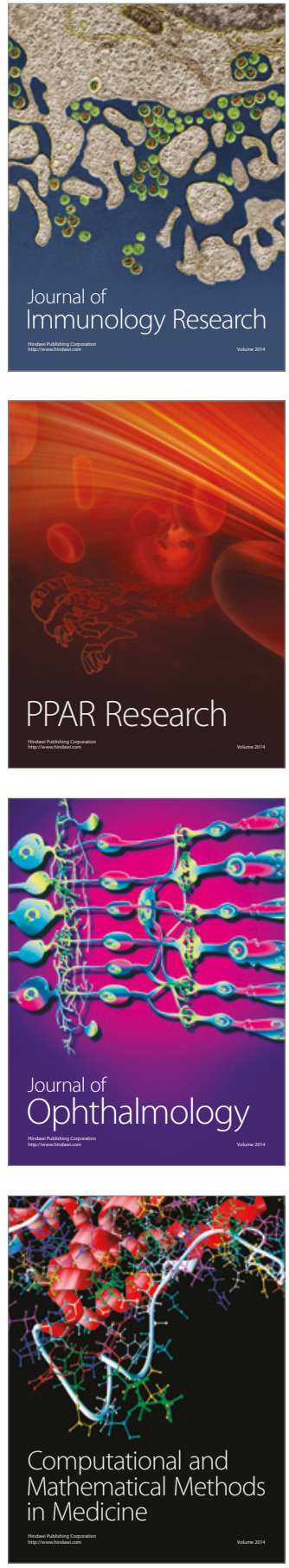

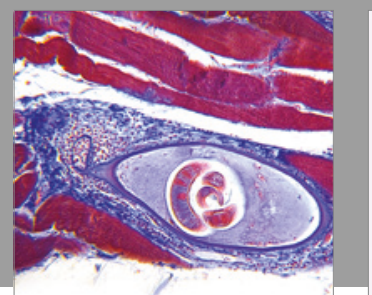

Gastroenterology Research and Practice
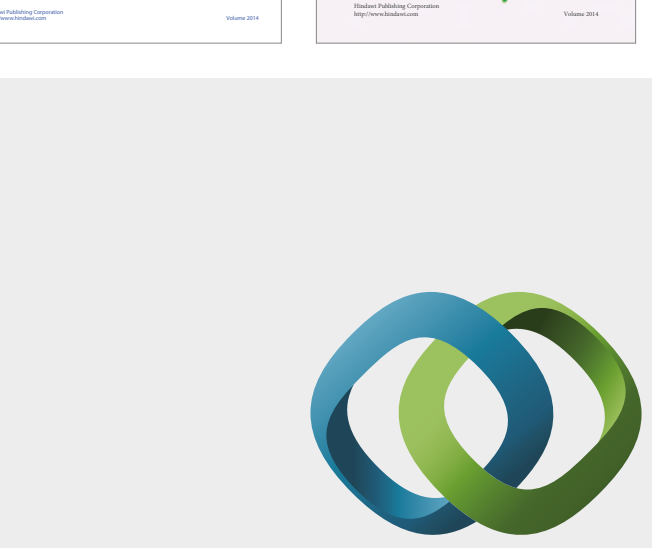

\section{Hindawi}

Submit your manuscripts at

https://www.hindawi.com
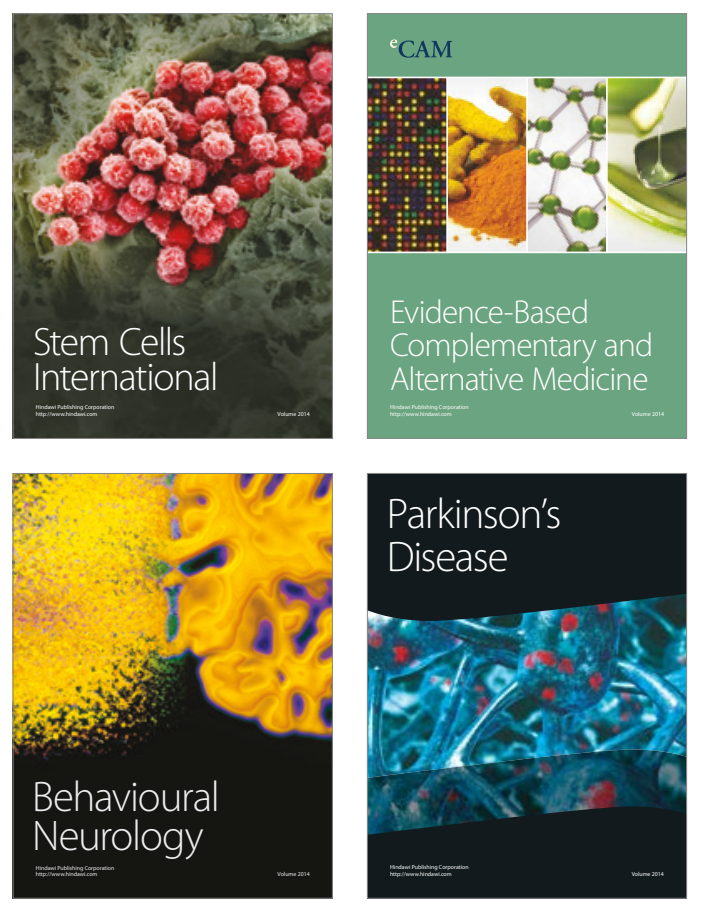
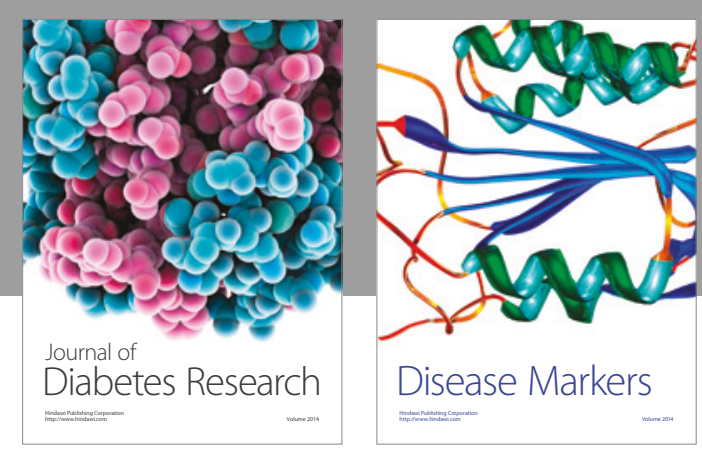

Disease Markers
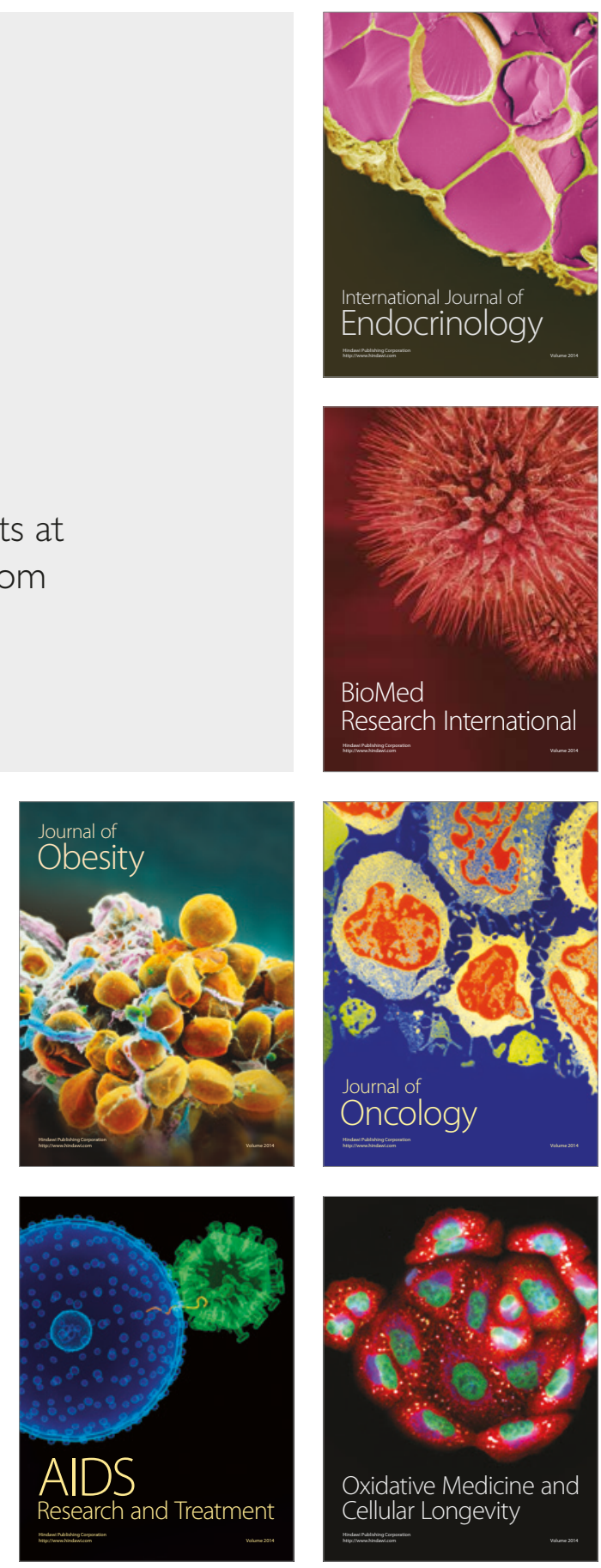